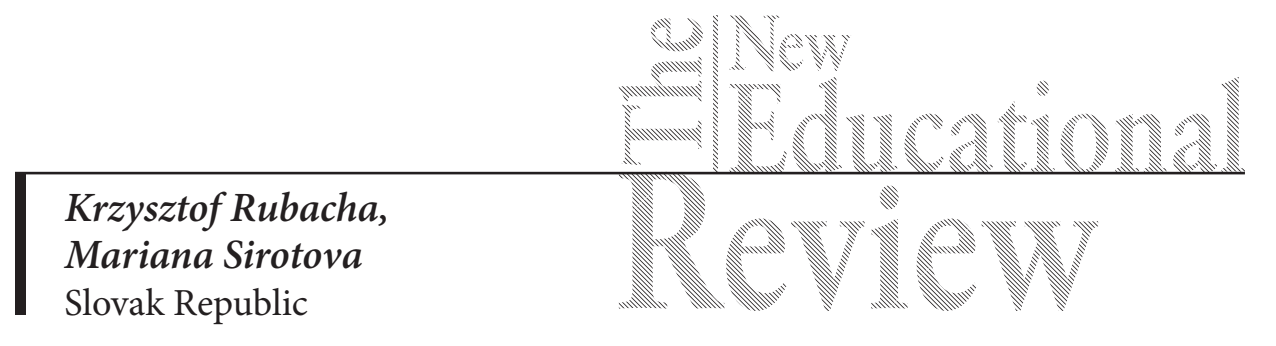

\title{
Child-rearing Practices in Slovakia - A Comparative Study
}

DOI: $10.15804 /$ tner.2015.40.2.01

\begin{abstract}
The article reports on empirical research into the differences in child-rearing practices between present-day families and families living at the turn of the $21^{\text {st }}$ century. The concept of child-rearing practices is addressed from the point of view of social theories of learning and socio-cognitive theories which constituted the basis for the research discussed. Results show that a portion of practices significantly differs in each group, and a portion remains unchanged. The biggest difference concerns 'deferment of gratification' as a factor for the development of many social skills. In the present-day family group this childrearing effect has largely disappeared.
\end{abstract}

Child-rearing practices are an essential factor in the activation of educational processes understood here as mechanisms of development. This claim derives from W. Mischela's (1973) social learning theory as well as K.Busseya and A. Bandura's (1999) socio-cognitive theory. Both theories focus on modelling as one of the main mechanisms responsible for learning behaviour considered as a socio-cultural standard. Accordingly, one can view child-rearing practices in general from two perspectives: from the point of view of formal development mechanisms, or in terms of the influential content triggering these mechanisms. Formal mechanisms of development should be seen as relatively constant and unchanging. Following the conventions adopted by neo-behavioural cognitive theories we can talk about learning through observation, direct learning, indirect experience or modelling (Bussey, Bandura 1999, p. 686). These processes, however, are realized through concrete content hidden in stereotypes, social reinforcement, social pressures, the stratification and segregation of the sexes, social sanctions, etc. (Chomczyńska-Miliszkiewicz 2002, p.91). While the mechanisms of development, 
from the formal point of view, are relatively unchanging, the content which triggers them changes over time. In this article, we try to look at educational practices from the point of view of this changing content. We would like to see how the content of educational influence has changed over the last 4-18 years, at the same time taking into account that it is realized through unchanging mechanisms of learning. Our question, therefore, is the following: what differences can be found in childrearing practices, including children's reactions to them, between contemporary families (2014-2015) and families at the turn of the $21^{\text {st }}$ century (from 1997). Why do we want to compare these two periods? Because the cultural transformation observed in precisely these periods is - owing to the technological developments in information and communication - more significant than that of earlier periods. The sheer spread of the use of mobile phones and the possibility of maintaining contact within a global network have introduced new qualities to the interaction between people. These advancements, in turn, have changed the cultural standards and values regulating the everyday affairs of all generations, and it is these same changes that we want to identify in family educational practices. To this end, we constructed a list of criteria for the analysis of child-rearing practices which, from the perspective of the (socio-cognitive and social learning) theories guiding this study, seem crucial for describing and clarifying educational processes. What is often mentioned in this context are the daily duties children living in family homes have, the role of the father and mother in raising children, whose behaviour children model, how parents react to their children's needs, how children react to their parents' needs, what parents' and children' attitudes are to religion, schools and teachers, how parents react to their children's lies and vice versa, how parents and children spend their free-time, how parents and children behave with regard to others, what child-rearing methods parents use, what punishments, what rewards, what children find precious, how much time parents and children spend with each other, what interests parents have and how they realize them, what children expect from their parents and vice versa, which of the parents has a stronger position in the family. In the presented study we will describe several of the above-mentioned criteria. We will focus, however, on children's daily duties, parents' contribution to child-rearing, the authority figure in the family, the reciprocal reactions of parents and children with regard to communicating their needs and expectations, the ways of spending free-time, parents' and children' attitudes toward school, as well as toward sexual education. These criteria will be the subject of comparative analysis of two groups of parents and children. 


\section{Method}

The study was conducted using quantitative strategies in a comparative scheme as a practical diagnostic study. It is, however, worth noting that the measurements of variables were undertaken on a nominal level, and therefore variables were identified qualitatively. Two samples (A and B) were selected for comparison. The first sample (A) focused on subjects who had the competency to analyze their own childhood and adolescent experiences. Therefore, university students taking teacher-training courses, who had several didactic classes in psychology and pedagogy under their belt, were among those chosen. These were undergraduate and graduate $(\mathrm{N}=112)$ students between the ages of 20-23, studying history, Slovakian philology, and pedagogy. Whereas, the second sample (B) was made up of subjects of both sexes and their children. The parents were between the ages of 28-46, whereas the children were between the ages of 7-17. The sample of university students (A) were asked to record their own childhood and adolescent family experiences based on an earlier agreed on set of criteria. This was, therefore, a guided attempt to garner insight into past familial and childhood interactions. All of the studied subjects worked at the same time in one location. There were no time limitations. Completion of the task took between 2 and 3 hours. A group of researchers, who, having previously completed schooling and subsequently passing the "pedagogical research" module, worked with the second group (B), conducting observations and interviews with the parents who were currently raising their children. The research consisted in ten-day observation of each family, conducted for three hours every day. The data were coded on special observation sheets and collected with the help of guided interviews and open conversation. One researcher was assigned to each family. In total, 53 elementary families were observed. It is worth noting that the students in group A described their childhood experiences starting from 1997, while the researchers observing the family's activities provided data for the years 2014-2015. The smallest difference separating the two sample groups was 4 years, and the biggest difference - 18 years. The median amounts to an 11-year difference between the childhood experiences and the data supplied by the observations undertaken in 2014-2015. We began the data analysis by coding the students' own descriptions of childhood experiences. This entailed conferring quality codes, which in themselves comprised indicators of the criteria for the analysis of childhood experiences, onto specific fragments of the text. Then, the material thus prepared was passed on to another researcher who had not participated in the study planning or data collection, but rather played the role of a competent judge, verifying the accuracy of the indicators identified in the 
codes. This triangulation of researchers ultimately allowed us to assemble verified analytic codes. Next, we counted the frequency of specific variables and, in turn, prepared the data for quantitative analysis. A similar approach was used with the data gathered from the observations and ethnographic conversations. The authors of this study also received the data in the form of a text, which included observation logs as well as transcripts of the ethnographic conversations and interviews. Firstly, we checked the quality of the gathered data, weeding out semantically vague and deficient or illegible material. We then proceeded to code the collected material, building codes which consisted of criteria indicators - variables, which the field researchers used. Similarly to the descriptions regarding the data obtained in the subjects' own recollections of experiences, the selected codes were subjected to researcher triangulation, abandoning a part of the codes or changing them. After this verification process we calculated the frequency of specific variations in the studied variables, preparing data for statistical analysis. As the level of the measured variables was nominal, we solely calculated the frequency and measurements of covariance understood as the probability sums of a given variant of the variable assessed - if it showed up as definite, then another variant was considered. This statistical effect was achieved by counting the values for a portion of the data from the chi-square test, taken as a test determining the relevance of differences between the groups (data from samples A and B). However, as mentioned above, the study was conducted using quantitative strategies in a comparative schema. We also used elements of qualitative research, both during the data collection phase (the elements of observations and ethnographic interviews) and data analysis (coding data and identifying qualitative indicators) as well as the interpretation of data ( invoking significations behind the identified child-rearing practices).

\section{Analysis and Interpretation of Results}

The results will be analyzed with regard to specific categories describing familial child-rearing practices. The two groups of participants in the studies yielded similar data regarding the daily duties children were to do. Among the most frequently observed duties were keeping one's own room tidy and sporadic cleaning of the whole house, usually on a Saturday. Doing one's homework figured as the main responsibility in both groups, while a quantitative difference was noted in the dimension of this phenomenon. Sample B, the contemporary group of parents, clearly placed more pressure on their children fulfilling their school responsibilities than group A, the group whose task it was to analyze their past childhood experiences. The values of the chi-square test were statistically significant $-\mathrm{p}<0.05$. The 
qualitatively coded data, in turn, show that the observed children used the phrase: 'I'm doing my homework now' as an alibi, allowing them to shirk other daily duties. This phenomenon had also been the experience of the A sample, however, in the case of this group, the parents had not allowed themselves to be tricked, which is also true for the present-day mothers and fathers. Our research observers (group B) also provided us with data which show that the contemporary parents spend more time with their children than the studied subjects who reconstructed their past childhood experiences (A) $(\mathrm{p}<0.05)$. The difference is significant and works in favour of sample group B only when the children are under 12 . The time together is for the most part spent doing homework, which could mean that this effect does not translate to building up deeper relations between parents and children, but rather shows the parents' desire to stimulate their child's academic achievement. This is of course only our interpretation, and not the results of the analysis. Keeping with this issue, we can look at the data concerning the roles of both the fathers and mothers in raising their children. In terms of content, and thus the area of the parents' involvement, the role of the mother is identical in both sample groups. The focus is on securing the child's needs: those pertaining to care, education, cognitive needs, emotional needs, and social needs. What also emerges, however, are differences in the fulfilment of the father's role. In terms of quality there is a new area of paternal involvement, mainly taking responsibility for child care. Some of the observed fathers in study group B took part in feeding their children, changing nappies, cooking, putting the children to bed, and taking them for walks, all of which the fathers from sample group A did not do. The frequency of such activities rises with the decreasing age of the fathers studied. One could, therefore, aver that this is a new phenomenon, concerning, as it does, not the entire contemporary group of fathers, but mainly those whose children are under the age of 3. Generally, this difference holds up, which means that the likelihood of a new style of paternal involvement is on the rise if we look to the analysis of study group B - it is on the decline, however, if we focus on the analysis of frequency in study group A.

Comparing the time the fathers in both sample groups spend with their children presents the group of present-day fathers favourably. In the materials obtained from the analysis of their own past childhood experiences (A) we find the prevalent phrase: 'father was away from home and focused on securing material means for the family', 'he was not involved in raising the child on a daily basis'. On the other hand, no prevalence of this phrase is found among sample group B. Here, the data are more diversified and about $40 \%$ of the fathers declare having spent an amount of time at home similar to that of the mothers. What is somewhat 
surprising in this context is the rise in the children's attestations that mothers were their authority figures at home. Perhaps this effect can be clarified if we consider A. Bandura's writings on the topic of modelling. According to Bandura, children imitate the behaviour of the parent who experiences more social gratification because of his or her own career-orientated activities, as well as who and how he or she is (Bussey Bandura 1999, pp. 686-688). If we consider being the authority figure as synonymous with supplying children with a model to imitate, then the rising social status of women, their increasing commitment to their careers and the resulting social gratification they receive should strengthen their authority in the eyes of the child.

We obtained interesting data with regards to the mutual reactions of parents and children to each other's needs and expectations. Let us start with the extent to which parents meet their children's needs and expectations. What comes to the fore is a qualitative difference. A lot of the data collected from the group of present-day parents (B) was coded as 'immediate gratification' or as 'immediate fulfilment of the child's expectations'. Categories such as these were not coded in study group A, i.e., in the recollections of past childhood experiences by the present-day students. In the course of the analysis both codes were combined into one whose frequency was very high and reached 69\%. A transformation such as this in the span of 11 years could be treated as significant. Moreover, we noticed that the parents in sample group B fulfilled their children's expectations almost 'literally. The children do not have to wait for anything, they do not have to work to earn their rewards (we will return to this point) and are growing more impatient. This last finding was confirmed by the research observers who studied the family lives of the subjects. Shoda's findings indicate, however, that early deferment of gratification in child-rearing strongly correlates with the level of achievement in secondary school as well as at work later in life, whereas immediate gratification generates child-rearing and social functioning problems in adulthood. Mischel added that children who defer gratification in their pre-school years become more careful teenagers managing to concentrate, express their thoughts and react to argumentation (Shoda, Mischel, Peake 1990, pp. 979-985). These findings were identified in longitudinal studies, spanning several years, and belong to some of the best documented developmental psychology. Of course, the calculated coefficient of difference between groups chi-square is high and statistically significant $(\mathrm{p}<0.05)$. From the perspective of development, the probability of the parents' proper conduct in this area decidedly falls when we shift from the results of sample A to sample B. In as much as in sample B children had to earn their parents' recognition, in sample A they were aware that their needs were at the centre of family 
life. This, however, does not translate to the children's ways of reacting to their parents' expectations. What we have in mind here is the sample of present-day families. A portion of the observational data regarding these families was coded as: 'lack of a positive reaction to parents' expectations'. This concerned the data describing the parents' expectations with regard to their child's behaviour toward strangers, in public places, the interaction between parents and children, as well as the fulfilment of daily duties. From this code we disabled expectations connected with academic achievement. Perhaps when it comes to academic achievement parents are less likely to ignore their children's behaviour, whereas in previous examples they are more likely to acquiesce. It is difficult to give an unequivocal interpretation of this state of affairs. However, we can get wind of the parent's part in the mechanism's trajectory. The students described their past family relations in terms of soliciting for their parents' acceptance. In general, what was mentioned were the exchanges between the parents and children; and it was this connection that the children grasped. The recorded change deserves monitoring and studying under the auspices of research strategies involving a random assortment of representative samples which would allow for a diagnosis on the level of a population. What the extent of this dangerous phenomenon is among the population we do not know. Keeping to our analytical perspective, however, it is worthwhile at this point to look into the data describing the attitudes of parents and children to school.

The parents showed a strong belief in the academic success of their child (71\%). A high rate of academic success was perceived as a bridge to attaining a successful, because affluent, adulthood. Connected with this is the focus on achievement in all possible disciplines. School is perceived as a place for winning academic trophies. This market-based rationale, seeing school as a departure point leading to a life of consumerism, was not yet present in sample A, although a portion $(23 \%)$ of the data allowed us to codify it in exactly this way. The dominant attitude, nevertheless, was one in which the parents treated school as a place of learning and peer-play for their children. Academic marks were important. However, what was equally as important was the child's behaviour in school and his or her developing relationships with others. These qualitatively varied results translate into a quantitative variation confirmed by the statistically significant chi-square coefficient. What do the children think of school in this context? In each of the studied groups, the attitudes of the children toward school were identical to their parents' attitudes. In sample group A the subjects reconstructed their attitudes toward school using the same terminology in which they described their parents' attitudes. A similar situation was observed in regards to the present-day families. This seemed to be more 
a modelling of the parental attitudes by the children than the latter demonstrating their own original views on the subject.

The next pool of criteria for comparing child-rearing practices between each group concerned extracurricular contexts. It dealt with, among other things, the ways in which the children and parents spent their free-time. It should be mentioned here that no qualitatively or quantitatively significant differences were noted in the parent group between the parents in group A, about whom the studied student subjects had written, and the parents in group B, whom the students, in the role of researchers, had studied. In both cases the parents spent their free-time taking care of their children, and visiting their families and friends, time permitting, at the end of the week. However, the present-day parents travelled outside of Slovakia slightly more often than in the present-day students' recollections. Although this did not present a statistically significant quantitative difference, it was, however, perceptible as a quantitative category. On a daily basis, however, the parents had almost no free-time, because the researchers did not include the time spent, specifically by the women, running the household in free-time. The fathers in both generation-groups devoted most of their time to work. However, a change was noted in the manner in which the children spend their free-time. The time spent outside of the home in a physical sense, e.g., at a playground, was decidedly reduced. The present-day children spend their time for the most part at home in front of their computers. With respect to both categories, i.e., the time spent outside of the home and the time spent in front of the computer, a statistically significant difference was found between groups A and B $(\mathrm{p}<0.05)$. Group A spent more time outside of their homes, while group $B$ spent more time in front of their computers. It should be added that the children from group A, i.e., the present-day students writing about their own childhood experiences, also had computers at home with games installed on them. The children from group B, however, lived on the net, spending a lot of time on social networking websites. Through these websites, they establish contact with their peers. In some sense, one can say that these children also spend time outside of their homes, yet this is a virtual environment, perhaps an analogy of the old playground. Besides, children find in this environment a source of more and more information about the world. This situation particularly pertains to the sexual sphere of teenage life, as it is teenagers that our analysis now concerns. Both the studied groups A and B could not rely on their parents to transmit knowledge about sexuality. In a word, there is no difference between the two studied groups in terms of a lack of sexual education at home. To this day this topic remains a taboo sphere for the studied families (Chomczyńska-Rubacha 2010, pp.147-162). Nowadays, young people acquire this 
knowledge on the Internet, whereas in the past (group A) it was acquired from peers and older friends.

The findings presented here, comparing educational practices in both groups is not focused solely on differences. Certain similarities between the two groups were also revealed, ones which in fact indicate a lack of change despite the changing external conditions. This cursory analysis shows, however, that educational practices are not undergoing revolutionary changes, but are rather evolving, and quite unevenly. There are, however, a few differences which, from the point of view of knowledge on childhood developmental processes and growing up, in the future can bring unexpected consequences. Without a doubt, what we find here is an almost complete lack of 'deferring gratification' and almost 'unconditional satisfying of children's needs by parents', combined with parents' acceptance of children not fulfilling their expectations. These findings demand deeper (quantitative) and broadened (quantitative) studies.

\section{References}

Bussey K., Bandura A. (1999). Social cognitive theory of gender development and differentiation. "Psychological Review", 4.

Chomczyńska-Miliszkiewicz M. (2002). Edukacja seksualna w społeczeństwie współczesnym. Konteksty pedagogiczne i psychospołeczne. Wydawnictwo UMCS Lublin.

Chomczyńska-Rubacha M. (2010). Standardy rozwojowe edukacji seksualnej. "Studia Edukacyjne" 12/2010.

Mischel W. (1973). Toward a cognitive social learning reconceptualization of personality. "Psychological Review", 80.

Shoda Y., Mischel W., Peake P.K. (1990). Predicting adolescent cognitive and self-regulatory competencies from preschool delay of gratification: Identifying diagnostic conditions. "Developmental Psychology" 26. 